\title{
Recognising the impact of traditional herbal medicine in managing cancer: The South African context
}

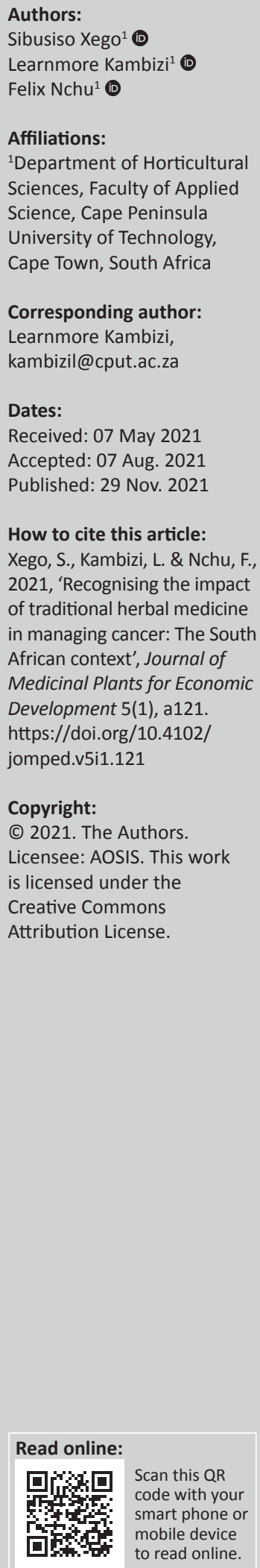

Background: The increasing prevalence of cancer is placing enormous pressure on health infrastructure globally. The ever rising cancer burden is not unique to South Africa but also to many low- and middle-income countries. Natural plant-based products have for long have been used traditionally for treating cancer. Approximately $7 \%-48 \%$ of cancer diagnosed patients take herbal medicines post diagnosis. As herbal remedies are also used by South Africans, it is justifiable to investigate herbal medicinal use in the prompt detection as well as prevention of cancer.

Aim: The aim of this article is to highlight the potential of South African medicinal plants to combat cancer.

Method: This review summarises previous research (1991-2020) on the impact of traditional herbal medicine in managing cancer, and identifies the context between traditional and conventional medicines. Scientific databases such as Science Direct, PubMed, Research Gate, and Google Scholar were used to source primary and secondary data for this review.

Results: The findings of the present study call for the integration of herbal medicines into the existing healthcare systems to encourage the open use of herbal medicines by cancer patients. In addition, this study revealed 19 medicinal plant species from 15 families that are commonly used for the management of cancer in South Africa's nine provinces.

Conclusion: It is crucial to enhance collaboration between the existing healthcare systems and herbal traditional medicines in the provision of better care to patients at risk of, or who have been diagnosed with, cancer.

Keywords: medicinal plants; combat cancer; healthcare; conventional medicine; traditional medicine; anti-cancer therapies.

\section{Introduction}

Cancer is one of the rising critical and concerning health problems that Africa faces today with predictions that incidences could double by 2030 (Edwards \& Greeff 2017). Approximately 13\% of the global mortality is caused by cancer, which accounts for 8.8 million deaths worldwide, with nearly 590000 occurring in Africa (Ly 2018). In South Africa, cancer affects at least one in four people, regardless of age, gender and or ethnicity (Glynn \& Bhikha 2016). Cancer is the number one dreaded disease for most South Africans and their greatest fear in terms of health (Glynn \& Bhikha 2016).

Africa continues to suffer from infectious diseases. But cancer dominates the total sub-Saharan African burden of disease. It is predicted that between 2010 and 2030, cancer cases will have risen by $85 \%$ in the region (Morhason-Bello et al. 2013). Cancer as a global health crisis accounts for approximately $70 \%$ of deaths in low- and middle-income countries alone (Kuruppu, Paranagama \& Goonasekara 2019). About 181 and 96 million new cancer cases as well as mortalities were, respectively, reported in 2018, with a projection of nearly 30 million cases by 2040 based on the current cancer burden statistics (Sewram 2019). On an average, one in five men and one in six women worldwide will develop cancer during their lifetime, whilst one in eight men and one in 11 women will die of cancer (Sewram 2019). A report by the Cancer Association of South Africa indicates that one in four South Africans will be affected by cancer in their lifetime (Science in Africa 2008).

Regrettably, the African continent remains unable to cope with the persisting cancer scourge because of limited resources amongst other factors (Sylla \& Wild 2012). African healthcare systems are struggling under the weight of this growing cancer crisis. In fact, over $20 \%$ of the African 
countries have no access to cancer treatments at all, whilst access is limited and irregular in other countries (Dent et al. 2017). Even though South Africa has prevention programmes, educational initiatives and advances in cancer treatment, an increase in cancer incidence is still notable. The increase in the incidence of cancer calls for the expansion of preventative efforts (Steyn \& Muller 2000).

Many patients, especially those in developing countries, continue to seek traditional and allopathic therapies concurrently. Increasingly, people are turning to traditional medicine because of many reasons, including prohibitive costs, limited cancer treatment options and allopathic treatment side effects that are often unpleasant and or serious. Therefore, the aim of this article is to highlight the prospects of the South African traditional medicine and medicinal flora to complement allopathic medicine to combat cancer for future research and development.

\section{Methodology}

This review summarises previous research (1991-2020) on the impact of traditional herbal medicine in managing cancer and generated a list of some species that have traditionally been used to manage and treat cancer in South Africa. The following keywords were employed to glean for information from literature: 'medicinal plants', 'combat cancer', 'traditional medicine', 'conventional medicine' and 'anticancer therapies'. Scientific databases including Google Scholar, PubMed, Science Direct as well as Research Gate were specifically used to source primary and secondary data for this review. Furthermore, taxonomic verifications of the plants were interrogated by use of the database of plants (http://www.theplantlist.org/).

\section{Allopathic medicine in South Africa}

In South Africa, the primary healthcare system is based on allopathic medicine (Mothibe \& Sibanda 2019). Allopathic medicine (western, orthodox, conventional or modern medicine) entirely relies on theories that are based on biochemical reactions (Latif 2010). Since the introduction of allopathic medicine in South Africa by the colonialists, two distinct forms of healthcare are apparent, namely, the western medicine (scientific based) and the indigenous traditional medicine (magico-religious based) (Latif 2010).

Whilst modern medicine may be efficient for treating several ailments, it is not always tailored to suit indigenous needs (Ouellet et al. 2018). The shortage of medicine affects the majority of countries in the world. As South Africa strives to achieve universal access to healthcare, the shortage of medicine, especially in public health institutions, is a major concern (Modisakeng et al. 2020). Patients die from easily treatable diseases because of chronic shortages of critical drugs in public health facilities. Although insurance schemes have been employed in many developing countries, including South Africa, to increase drug affordability, the outcomes of this initiative have not been as positive as expected (Pheage
2017). This is because of a host of factors including administration, which turns out to be a nightmare.

South Africa has made great efforts to improve primary healthcare since independence in 1994. But several issues have arisen in relation to public institutions including prolonged treatment waiting time because of shortage of human resources, equipment, the sluggish primary healthcare restructuring exercise as well as the disease burden which continue to increase (Maphumulo \& Bhengu 2019). Furthermore, the barriers that face the poor and marginalised rural communities to access healthcare cannot be overemphasised. These barriers include inadequate transport, finances, distance to the nearest facility and limited services (Gaede \& Versteeg 2011). Because of very low costs, and ease of access to traditional medicines, many Africans are forced to resort to this diverse healthcare system when they are unable to access modern medicines (Pheage 2017).

\section{Traditional practices and medicinal plants}

\section{Use of traditional medicine in the African context predominantly in South Africa}

Traditional medicine, also known as ethno-medicine, folk medicine, native healing or complementary and alternative medicine, is the oldest and still the most widely used form of healthcare that has stood the test of time (Abdullahi 2011; Ozioma \& Chinwe 2019). McFarlane (2015) and World Health Organization (2013) define traditional medicine as the sum total of the knowledge, skill and practices based on theories, beliefs and experiences indigenous to different cultures, whether justifiable or not, used in the maintenance of health as well as in the prevention, diagnosis, improvement or treatment of physical and mental illness.

The existence of traditional African herbal medicines is as old as the story of creation. This healthcare system continues to serve a vast number of people, especially the poor and the marginalised rural dwellers (Ehlers 2000). For centuries, hospitals and clinics were not readily accessible in rural areas, and people resorted to traditional medicine for survival (Magoro, Masoga \& Mearns 2010). Ethno-medicine is an ancient and culture-bound method of healing that humans have used to cope and deal with various diseases and common ailments that have threatened their existence and survival (Abdullahi 2011; Matsheta \& Mulaudzi 2008).

Besides South Africa, the sub-Saharan Africa region, the rest of Africa ,and most parts of the world in general also make use of traditional medicine for health. This form of healthcare has been practised since time immemorial and over generations by indigenous populations belonging to particular groups or cultures (Bhikha \& Glynn 2013). In South Africa, the use of plants as medicinal remedies remains an integral and important part of the people's traditions and culture, and this is expected to persist into the known future (Brandt et al. 1995; Smith 2003). To corroborate this point, 
traditional healing has been found to be concentrated a lot in the rural areas because of the inclination towards traditional ways of living in those areas. However, in the 21st century, the situation has changed with traditional healthcare spreading into urban and semi-urban areas (Mokgobi 2013).

The report of Ly (2018) indicated that availability and affordability of traditional medicines are the major driving forces for their exploitation. It is interesting to note that the current with recent and remarkable advancements in modern medicine do not mean much to many people in developing countries as traditional medicine still provides for their primary healthcare needs (Ayele 2018). In fact, new drug discoveries and synthesis of new formulations for use in primary healthcare systems in various countries including the developed countries are based on herbal traditional medicines (Priya et al. 2015). It is evident from the extent to which traditional medicine is practised that it cannot be ignored by those involved in the transformation and strategic planning of healthcare systems (Meissner 2009).

\section{Contest between traditional and conventional medicines in managing cancer}

Although a sizeable number of cancer patients rely on both traditional and western medicine, reports indicate that between $7 \%$ and $48 \%$ of these patients take traditional herbal medicines post diagnosis (Gratus et al. 2009). According to Ly (2018), cancer patients either use traditional medicines alone (monotherapy) or when available, in conjunction with western medicine (polytherapy). The increased usage of alternative or complementary medicine is on an increase globally amongst cancer patients (Puataweepong, Sutheechet \& Ratanamongkol 2012). These dynamics show the inborn human instinct to source for alternative solutions to a problem if the current one is not bearing intended results. In this case, the perceived failure of western medicines to deliver intended results in cancer patients pushes the patients towards these alternative therapies (Aliyu et al. 2017). In South Africa, the shortage of trained western medicine inclined health personnel in public health institutions is a major concern (Mokgobi 2013). Generally, herbal traditional medicine is the first-line therapeutic method after diagnosis, and in some areas with insufficient medical care, it might be the only option. Cancer patients amongst African populations tend to engage in this behaviour because of the shortage of a good and reliable primary healthcare system in their localities (Ly 2018). Priya et al. (2015) reported that modern drugs for the treatment of cancer reported more side effects in treated patients. Likewise, though patients may choose the best individual strategies for them based on their preferences, it is important to be aware of the limitations of unproven treatments (West 2018). Similar to orthodox medicine, herbal medicine has its own set of challenges such as the lack of sufficient research especially claims, and the safety of the herbal medicine. The production of reliable herbal medicines of consistent quality is also a major challenge. The risk of misidentification of medicinal plants and misdiagnosis of cancer is always imminent (Smith 2003). Herbal medicine can be toxic and may be harmful when used either alone or in combination with standard anticancer therapies (West 2018). Despite these challenges, African traditional herbal medicine may have a bright future, which can be achieved through collaboration, partnership and transparency in practice, especially with conventional health practitioners (Ozioma \& Chinwe 2019). Furthermore, such collaboration can increase service and healthcare provision.

\section{Use of medicinal plants as anticancer therapies}

The abundance of chemical diversity in millions of plant species makes nature an attractive source of new therapeutic compounds (Priya et al. 2015). Several African plants have found their way to modern medicine. These plants, whose traditional uses date back to ages, have been an essential source and component of modern drugs, developed through modern and cutting-edge scientific methods (Ozioma \& Chinwe 2019). In addition, plants are becoming popular because of their anti-cancer effects owing to progress made in phytochemical studies of herbal medicines (Kooti et al. 2017).

There are several plant-derived compounds with anti-cancer properties that are successfully employed in cancer treatment, and may suppress the disease completely (Priya et al. 2015). Some examples of commonly used herbal medicines for cancer management in South Africa are shown in Table 1. Modern western medicine relies on cutting edge pharmaceutical techniques that isolate active ingredients from medicinal plants and synthetically produce them in the laboratory, whilst traditional herbal medicine mainly relies on folkloric evidence that is normally passed down from generation to generation (Pal et al. 2015). The discovery of cancer drugs dates to the 1960s, with vincristine, vinblastine, camptothecin and taxol amongst the discoveries (Priya et al. 2015).

Conventional doctors rely heavily on plant-based medicines and an increasing number of prescriptions are plant-based (Kubukeli 2000). These herbal traditional remedies have attracted the attention of many fields of biological scientific research (Ly 2018). Many plants such as the Podophyllum peltatum (May-Apple), Colchicum autumnale L. (autumn colchicum) as well as Crotalaria sessiliflora L. have been shown to possess anti-cancer activities and their ethnomedicinal uses are thus validated (Hassim, Heywood \& Berger 2007). The traditional use of Dicoma capensis, a low-lying herb of the arid areas of Namibia and South Africa by the Khoisan people of these regions in the treatment of cancer dates back to ages in time. The recent discovery of the cytotoxic effects of D. capensis on breast cancer cells further validates this plant's potency and importance (Maness, Goktepe \& Ahmedna 2012). Several plant-derived compounds have been successfully isolated and are currently employed in cancer treatment. Some of the most significant examples include: the vinca alkaloids, the podophyllotoxins, camptothecins, tannins, betulinic acid, and the taxanes (Essack 2006; Iqbal et al. 2017; Lerata 2018). Lerata (2018) also highlighted a few of the common antibiotics derived natural 


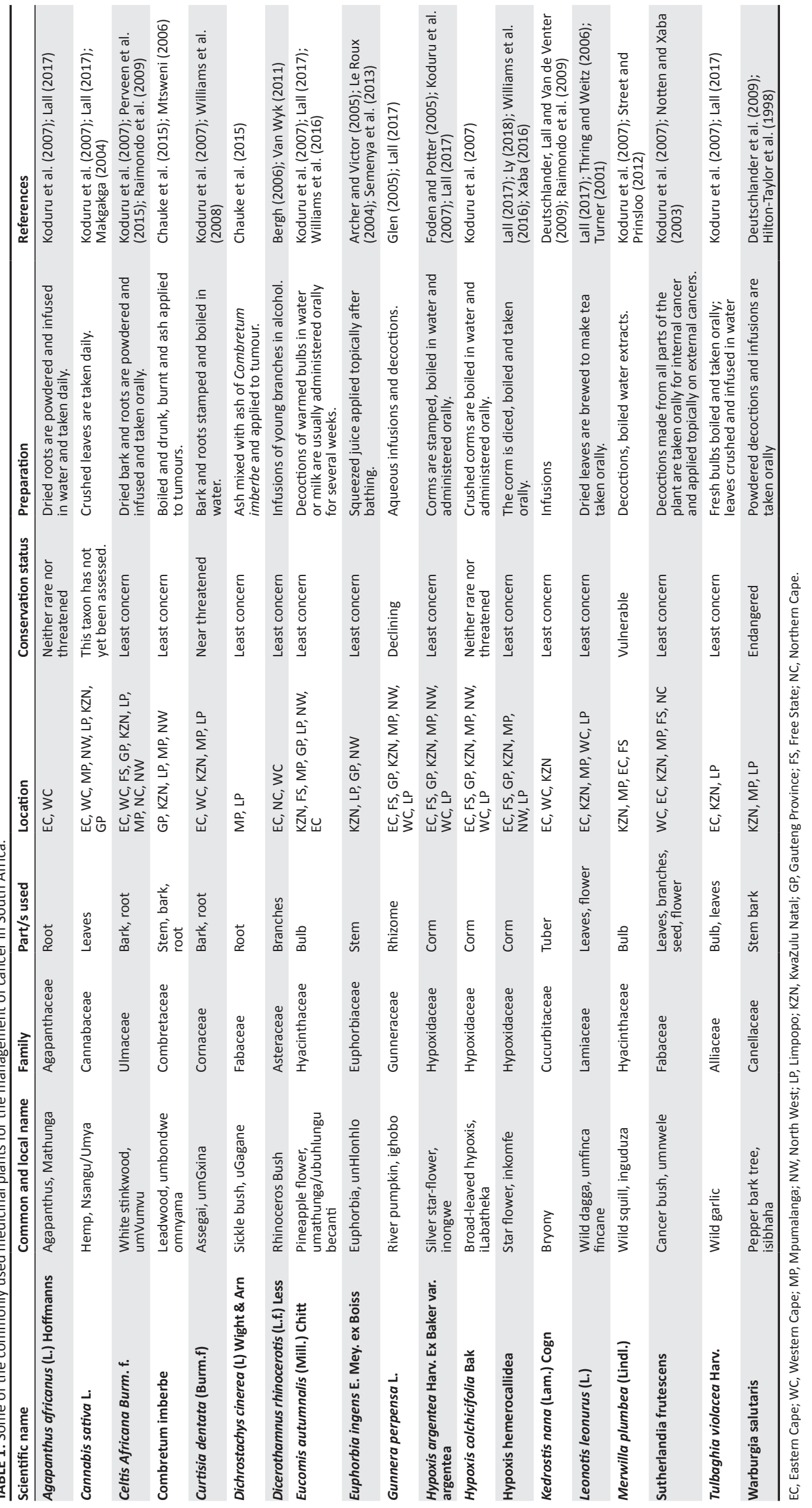


products used in cancer treatment such as anthracyclines, bleomycins and actinomycins.

The kingdom plantae is well endowed with a rich and wide range of antioxidants such as vitamin $C$, vitamin $A$, curcumin, epicatechin, verbascoside, quercetin, flavonoids, glycosides, resveratrol, taxols, genistein, calceolarioside, polyphenols, baicalein, gallic acid and lovastatin amongst other compounds, from which cancer therapy and chemoprevention can be extracted and used (Elnour et al. 2018; Greenwell \& Rahman 2015; Valadez-Vega et al. 2013). These antioxidants have the potential to inhibit the cell proliferation of different cancer cells such as colon cancer, breast, cervix, liver, skin, fibroblasts and many other malignant cells. Secondary metabolites such as polyphenols, flavonoids and brassinosteroids have been studied for their potential use as anti-cancer agents. Compounds including sulforaphane, isothiocyanates, isoflavones and pomiferin have shown to inhibit important targets in breast cancer proliferation (Greenwell \& Rahman 2015).

Antioxidants are substances that may protect cells from damage caused by unstable molecules known as free radicals (Hamid et al. 2010). The consumption of antioxidants such as vitamin $C$ has been linked to a reduced risk of breast cancer (Sant et al. 2018).

There are relatively few branded herbal-based anti-cancer products in the market for cancer management. For example, honeybush tea made from Cyclopia genistoides has proven health benefits including antioxidant and anticarcinogenic activity. Hypoxis phytosterols were developed into a branded product (Harzol®) from Johannesburg and this product is made from Hypoxis hemerocallidea with the main active compound rooperol which has patented anti-cancer activity (Van Wyk 2011). Also, Sutherlandia capsules from the Western Cape Province have been developed from Sutherlandia frutescens. The constituents of $S$. frutescens are a rich source of amino acids, canavanine, the cyclitol, pinitol, a variety of flavonols and triterpene glycosides. The biological activities of this plant are well-documented and support its continued use as a tonic by cancer patients (Drewes 2012).

Despite the popularity and potential of many medicinal plants used in the treatment of cancer, there is still little scientific evidence to support their anti-cancer activities (Alves-Silva et al. 2017). There is a dearth of literature on herbal parts that are used in cancer treatment in South Africa (Steenkamp \& Gouws 2006). Very few traditional medicines have been properly researched. It is, therefore, generally impossible to know which of them have health-promoting attributes, or what interactions whether positive or negative they may have with other medicines (Hassim et al. 2007). Therefore, to determine if these plants are capable of treating cancer and validate their anti-cancer benefits, both therapeutic approaches need to integrate their knowledge and conduct research on currently used medicinal plants (Figure 1). Figure 1 illustrates the potential solutions and benefits of integrating traditional medicine with conventional medicine to combat

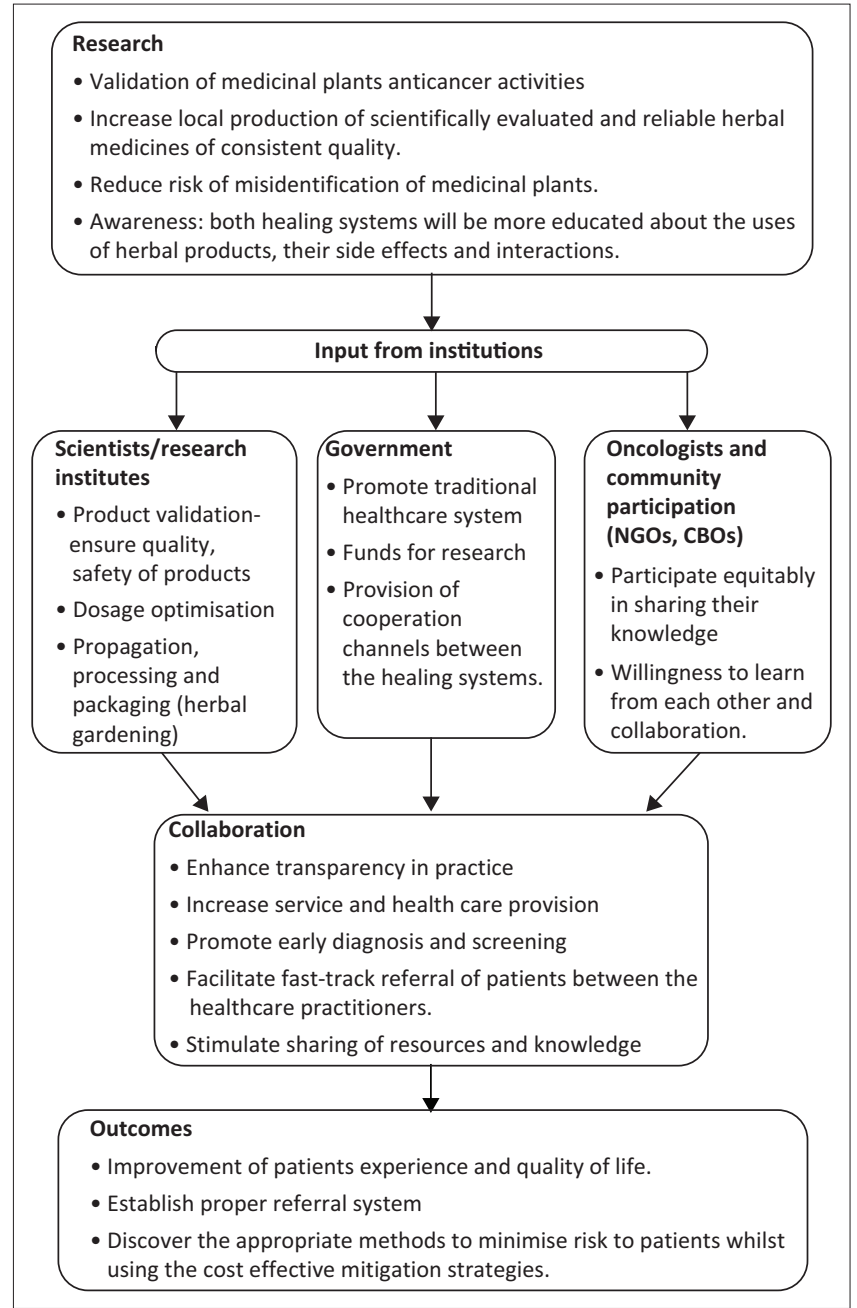

CBO, Community Based Organization; NGO, Non-Governmental Organization.

FIGURE 1: Integrating traditional medicine with conventional medicine to combat cancer in South Africa (potential solutions and benefits).

cancer. This integration has the potential to encourage the open use of herbal medicines by cancer patients as well as education.

\section{Combination of therapies (traditional and allopathic)}

Traditional and allopathic medicines are frequently viewed as separate entities. It is concerning that the simultaneous use of both healthcare systems by cancer patients in South Africa is often ignored (Trimble \& Rajaraman 2017). In the developing world today, the inclusion of herbal traditional medicines as part of the healthcare system is primarily to encourage a wider scope of primary healthcare delivery. After all, about $80 \%$ of Africans make use of this healthcare system as a first choice in the treatment of various irredictions (Bhikha \& Glynn 2013; Elujoba, Odeleye \& Ogunyemi 2005). Medicinal plants are often used to treat common diseases such as cancer, making this disease one of the most significant genetic diseases in the world (Koduru, Grierson \& Afolayan 2007). Medicinal plants play a key role in anti-cancer product development because they are good sources of natural and organic anti-cancer agents (Kuruppu et al. 2019). 
Nearly $70 \%$ of the world's population cannot afford modern cancer medications (Kuruppu et al. 2019). Aside from their high cost, most cancer therapies are partially effective and exhibit toxicities that are unbearable (Tavakoli et al. 2012). Currently, in spite of their efficacy claims, there are many western drugs in the market which have several side effects (Ozioma \& Chinwe 2019). The conventional medical system has with partial success spent a great deal of money trying to eradicate this major health issue with potent drugs, intense radiation and radical surgery (Glynn \& Bhikha 2016). In South Africa, it is, therefore, not surprising to see cancer patients undergoing radiation therapy still seeking herbal interventions from traditional healers with a belief that herbs will be much more effective (Matsheta \& Mulaudzi 2008).

Research on indigenous knowledge and traditional medicine will improve rural populations' access to drugs and scale up production of scientifically evaluated traditional medicines (Ozioma \& Chinwe 2019). Therefore, more research is required on herbal medicines to ensure that they reach their full therapeutic potential (Tavakoli et al. 2012). Because traditional plant medicines play a crucial healthcare role in the lives of South Africans, particularly in black communities, it is crucial to investigate and understand the possibility of including the use of herbal medicines in the prevention and prompt detection of cancer. This perception can potentially lead to development of collaboration models that encourage a cordial relationship amongst the existing healthcare systems, and will stimulate the collaborative effort needed to provide the best care to those at risk of cancer and or those already diagnosed with this disease.

\section{Potential benefits of synergising and integrating both systems}

Public-private partnerships involving African governments, healthcare professionals, non-profit organisations and industry from developed countries are urgently needed to build a sustainable system to address the emerging cancer crisis (Dent et al. 2017). A comprehensive approach to cancer prevention and treatment is imperative for improving the health of South Africans, and this should incorporate both research and effective management strategies (Stefan 2015).

Integrating allopathic and traditional medicine has the potential to play a major role in the healthcare delivery system of the country (Opok, Addai-Mensah \& Wiafe 2013). With each system having its strengths and weaknesses, it is important to promote an effective relationship between the two healing systems to develop mutual respect and understanding. In addition, practitioners could improve their own practice by integrating some of the practices and ideas that are used by their peers and thus general healthcare quality and welfare of the society will potentially improve (Opok et al. 2013; Pretorius 1991).

Most traditional medicines are yet to be efficiently investigated and scientifically validated (Mothibe \& Sibanda 2019; Telles et al. 2014). The partial science-based evidence about the efficacy and safety of traditional medicine makes it important for governments to develop healthcare systems that include traditional medicine practice, research and development in South Africa. Formalising and standardising traditional medicine could help reduce toxicity and impurities amongst other issues. To fully accept traditional medicines, practitioners and scientists need a solid understanding of their pharmacology and toxicology (Mothibe \& Sibanda 2019). Moreover, in order to solve the problem of drug shortages or high costs, many health-oriented ministries are now encouraging the use of local medicinal plants for disease treatment (Fokunang et al. 2011).

\section{Conclusion}

Cancer has a significant health impact on the South African population and is on the increase. After modern primary healthcare system-based diagnosis, many cancer patients seek out traditional herbal medicine, or use both systems (traditional and conventional) to their benefit. Despite the existence of conventional medicine, herbal medicine continues to be a relevant form of primary healthcare.

However, several traditionally used medicinal plants have not been standardised and their mechanisms of actions are still unknown. Little is known about their potential interaction or effects when used in conjunction with chemotherapy and radiation therapy. Integration between the existing healthcare systems may help provide a holistic healthcare system that is based on patient needs. Research is needed on the attitudes of modern healthcare professionals and that of patients towards herbal medicines. Such information will be significant in helping healthcare professionals understand why patients use herbal medicines and facilitate the negotiation of harmless and effective medical treatment procedures. It is also important to know whether the use of herbal medicine either on its own or in combination with allopathic medicine has a negative or positive effect on patient's health. There is also a need to validate medicinal plant anti-cancer activities to incorporate these into South Africa's healthcare system. Continuous and consistent research support on the development of safe and effective cancer drugs from natural medicinal flora is also needed.

\section{Recommendations}

The government needs to encourage the integration of traditional medicine with conventional medicine and provide cooperation channels between the two healthcare systems. This will enhance transparency in practice and stimulate the sharing of resources and knowledge. Furthermore, this collaboration has the potential to enhance a proper referral system that will increase service and healthcare provision not only to cancer patients but also to other irredictions.

\section{Acknowledgements}

The authors acknowledge Cape Peninsula University of Technology: Department of Horticultural Sciences for their 
support and provision of study materials and computing resources.

\section{Competing interests}

The authors declare that they have no financial or personal relationships that may have inappropriately influenced them in writing this article.

\section{Authors' contributions}

S.X. was responsible for conceptualisation, investigation and writing or preparation of the manuscript. L.K. and F.N. were involved in planning and supervised the work. All authors provided critical feedback and helped shape the manuscript.

\section{Ethical considerations}

This article followed all ethical standards for research without direct contact with human or animal subjects.

\section{Funding information}

This work was supported by the National Research Foundation of South Africa (Grant number: SFH160716178683). The grant was assigned to Sibusiso Xego.

\section{Data availability}

Data sharing is not applicable to this article, as no new data were created or analysed in this study.

\section{Disclaimer}

The views and opinions expressed in this article are those of the authors and do not necessarily reflect the official policy or position of any affiliated agency of the authors, the Publisher/s.

\section{References}

Abdullahi, A.A., 2011, 'Trends and challenges of traditional medicine in Africa', African Journal of Traditional, Complementary, and Alternative Medicines 8(5S), 115-123. https://doi.org/10.4314/ajtcam.v8i5S.5

Aliyu, U.M., Awosan., K.J., Oche, M.O., Taiwo, A.O., Jimoh, A.O. \& Okuofo, E.C., 2017 'Prevalence and correlates of complementary and alternative medicine use among cancer patients in Usmanu Danfodiyo university teaching hospital, Sokoto, Nigeria', Nigerian Journal of Clinical Practice 20(12), 1576-1583. https://doi. org/10.4103/njcp.njcp_88_17

Alves-Silva, J.M., Romane, A., Efferth, T. \& Salgueiro, L., 2017, 'North African medicinal plants traditionally used in cancer therapy', Frontiers in Pharmacology 8, 383. https://doi.org/10.3389/fphar.2017.00383

Archer, R.H. \& Victor, J.E., 2005, Euphorbia ingens E. Mey. ex Boiss, National Assessment, Red List of South African plants version 2017, South African National Biodiversity Institute.

Ayele, T.T., 2018, 'A review on traditionally used medicinal plants/herbs for cance therapy in Ethiopia: Current status, challenge and future perspectives', Organic Chemistry: Current Research 7(2), 8. https://doi.org/10.4172/2161-0401.1000192

Bergh, N., 2006, Dicerothamnus rhinocerotis (L.f.) less, South African Biodiversity Institute, Compton Herbarium, Kirstenbosch.

Bhikha, A.H. \& Glynn, J., 2013, African traditional healing and Tibb. A science of medicine: The art of care, Tibb Institute.

Brandt, H.D., Osuch, E., Mathibe, L. \& Tsipa, P., 1995, 'Plants associated with accidental poisoned patients presenting at Ga-Rankuwa Hospital, Pretoria', South African Journal of Science 91(2), 57-59. https://journals.co.za/doi/pdf/10.10520/ AJA00382353_5162

Chauke, M.A., Shai, L.J., Mogale, M.A., Tshisikhawe, M.P. \& Mokgotho, M.P., 2015 'Medicinal plant use of villagers in the Mopani District, Limpopo province, South Africa', African Journal of Traditional, Complementary and Alternative Medicines 12(3), 9-26. https://doi.org/10.4314/ajtcam.v12i3.2
Dent, J., Manner, C.K., Milner, D., Mutebi, M., Ng'ang'a, A., Olopade, O.I. et al., 2017, Africa's emerging cancer crisis: A call to action.

Deutschlander, M.S., Lall, N. \& Van de Venter, M., 2009, 'Plant species used in the treatment of diabetes by South African traditional healers: An inventory', PharmaceuticalBiology47(4),348-365.https://doi.org/10.1080/13880200902752959

Drewes, S.E., 2012, 'Natural products research in South Africa: 1890-2010', South African Journal of Science 108(5-6), 17-24. https://doi.org/10.4102/sajs. v108i5/6.765

Edwards, L.B. \& Greeff, L.E., 2017, 'Exploring grassroots feedback about cancer challenges in South Africa: A discussion of themes derived from content thematic analysis of 316 photo-narratives', The Pan African medical Journal 28(1), 173 https://doi.org/10.11604/pamj.2017.28.173.11894

Ehlers, V., 2000, 'Nurses as advocates between western and traditional wealth practices in RSA'. Health SA Gesondheid 5(2), 29-36. https://doi.org/10.4102/ hsag.v5i2.29

Elnour, A.A.M., Mirghani, M.E.S., Musa, K.H., Kabbashi, N.A. \& Alam, M.Z., 2018 'Challenges of extraction techniques of natural antioxidants and their potential 'Challenges of extraction techniques of natural antioxidants and their potential 596. https://doi.org/10.21767/1791-809X.1000596

Elujoba, A.A., Odeleye, O.M. \& Ogunyemi, C.M., 2005, 'Traditional medicine development for medical and dental primary health care delivery system in Africa', African Journal of Traditional, Complementary and Alternative Medicines 2(1), 46-61. https://doi.org/10.4314/ajtcam.v2i1.31103

Essack, M., 2006, 'Screening extracts of indigenous South African plants for the presence of anti-cancer compounds', Doctoral dissertation, University of the Western Cape.

Foden, W. \& Potter, L., 2005, Hypoxis argentea Harv. Ex Baker var. argentea, Nationa Assessment: List of South African plants version 2017, p. 1, South African National Biodiversity Institute.

Fokunang, C.N., Ndikum, V., Tabi, O.Y., Jiofack, R.B., Ngameni, B., Guedje, N.M. et al., 2011, 'Traditional medicine: Past, present and future research and development prospects and integration in the National Health System of Cameroon', African Journal of Traditional, Complementary and Alternative Medicines 8(3), 284-295. https://doi.org/10.4314/ajtcam.v8i3.65276

Gaede, B. \& Versteeg, M., 2011, 'The state of the right to health in rural South Africa', South African Health Review 2011(1), 99-106.

Glen, R., 2005, Gunnera perpensa, South African Biodiversity Institute, KwaZulu Natal Herbarium, KwaZulu Natal.

Glynn, J.P. \& Bhikha, R., 2016, Tibb position statement on cancer, Tibb Institute, a science of medicine the Art of Care, Cape Town.

Gratus, C., Wilson, S., Greenfield, S.M., Damery, S.L., Warmington, S.A., Grieve, R. et al., 2009, 'The use of herbal medicines by people with cancer: A qualitative study', BMC Complementary Alternative Medicine 9(1), 14. https://doi. org/10.1186/1472-6882-9-14

Greenwell, M. \& Rahman, P.K., 2015, 'Medicinal plants: Their use in anticancer treatment', International Journal of Pharmaceutical Sciences and Research 6(10), 4103-4112. https://doi.org/10.13040/IJPSR.0975-8232.6(10).4103-12

Hamid, A.A., Aiyelaagbe, O.O., Usman, L.A., Ameen, O.M. \& Lawal, A., 2010, 'Antioxidants: Its medicinal and pharmacological applications', African Journal of Pure and Applied Chemistry 4(8), 142-151.

Hassim, A., Heywood, M. \& Berger, J., 2007, 'Health \& democracy: A guide to human rights, health law and policy in post', South African Journal on Human Rights 23(2), 403-406. https://doi.org/10.1080/19962126.2007.11864929

Hilton-Taylor, C., Scott-Shaw, R., Burrows, J. \& Hahn, N., 1998, Warburgia salutaris, The IUCN Red List of Threatened Species, International Union for Conservation of Nature and Natural Resources.

Iabal, J., Abbasi, B.A., Mahmood, T., Kanwal, S., Ali, B., Shah, S.A. et al., 2017, 'Plantderived anticancer agents: A green anticancer approach', Asian Pacific Journal of Tropical Biomedicine 79(12), 1129-1150. https://doi.org/10.1016/j. apjtb.2017.10.016

Koduru, S., Grierson, D.D. \& Afolayan, A.J., 2007, 'Ethnobotanical information of medicinal plants used for treatment of cancer in the Eastern Cape Province, South Africa', Current Science 92(7), 906-908.

Kooti, W., Servatyari, K., Behzadifar, M., Asadi-Samani, M., Sadeghi, F., Nouri, B. et al., 2017, 'Effective medicinal plant in cancer treatment, part 2: Review study', Journal of Evidence-Based Complementary \& Alternative Medicine 22(4), 982-995. https://doi.org/10.1177/2156587217696927

Kubukeli, P.S., 2000, 'Traditional healing practice using medicinal herbs', The Lancet 354, SIV24. https://doi.org/10.1016/S0140-6736(99)90367-7

Kuruppu, A., Paranagama, P. \& Goonasekara, C.L., 2019, 'Medicinal plants commonly used against cancer in traditional medicine formulae in Sri Lanka', Saud Pharmaceutical Journal 27(4), 565-573. https://doi.org/10.1016/j. jsps.2019.02.004

Lall, N., 2017, Medicinal plants for holistic health and well-being, 1st edn., Academic Press, Pretoria.

Lerata, M.S., 2018, Discovery of cytotoxic natural products from South African marine sponges, University of Western Cape, Cape Town.

Latif, S.S., 2010, 'Integration of African traditional health practitioners and medicine into the health care management system in the province of Limpopo', Doctoral dissertation, University of Stellenbosch, Stellenbosch.

Le Roux, L.N., 2004, Euphorbia ingens, Lowveld National Botanical Garden, South African National Biodiversity Institute, Nelspruit.

Ly, A., 2018, 'Traditional medicines and cancer therapies in African landscape', Journal of Tumor Medicine \& Prevention 3(1), 555601. https://doi.org/10.19080/
JTMP.2018.03.555601 
Magoro, M.D., Masoga, M.A. \& Mearns, M.A., 2010, 'Traditional health practitioners' practices and the sustainability of extinction-prone traditional medicinal plants', International Journal of African Renaissance Studies 5(2), 229-241. https://doi. org/10.1080/18186874.2010.534842

Makgakga, C., 2004, Cannabis sativa, South African National Biodiversity Institute, Pretoria.

Maness, L., Goktepe, I. \& Ahmedna, M., 2012, 'In vitro cancer research on ancient herbal remedies: A changing trend', Journal of Applied Pharmaceutical Science 2(8), 13-20. https://doi.org/10.7324/JAPS.2012.2802

Maphumulo, W.T. \& Bhengu, B.R., 2019, 'Challenges of quality improvement in the healthcare of South Africa post-apartheid: A critical review', Curationis 42(1), 1-9. https://doi.org/10.4102/curationis.v42i1.1901

Matsheta, M.S. \& Mulaudzi, F.M., 2008, 'The perceptions of traditional healers of cervical cancer care GA Mothapo village in Limpopo province', Indilinga: African Journal of Indigenous Knowledge Systems 7(1), 103-116. https://doi.org/10.4314/ indilinga.v7i1.26429

McFarlane, C., 2015, 'South Africa: The rise of traditional medicine', Insight on Africa 7(1), 60-70. https://doi.org/10.1177/0975087814554070

Meissner, O., 2009, 'Traditional medicine and its accommodation in the South African national health care system with special attention to possible statutory regulation', Doctoral dissertation, University of South Africa, Pretoria.

Modisakeng, C., Matlala, M., Godman, B. \& Meyer, J.C., 2020, 'Medicine shortages and challenges with the procurement process among public sector hospitals in South Africa; findings and implications', BMC Health Services Research 20(1), South Africa; findings and implications', BMC Healt
1-10. https://doi.org/10.1186/s12913-020-05080-1

Mokgobi, M.G., 2013, 'Towards integration of traditional healing and western healing: Is this a remote possibility?', African Journal for Physical Health Education Recreation, and Dance 2013(1), 47-57.

Morhason-Bello, I.O., Odedina, F., Rebbeck, T.R., Harford, J., Dangou, J.M., Denny, L. et al., 2013, 'Challenges and opportunities in cancer control in Africa: A perspective from the African Organisation for Research and Training in Cancer', The Lancet Oncology 14(4), 142-151. https://doi.org/10.1016/ S1470-2045(12)70482-5

Mothibe, M.E. \& Sibanda, M., 2019, 'African traditional medicine: South African perspective', Traditional and Complementary Medicine 1-27. https://doi. org/10.5772/intechopen.83790

Mtsweni, P., 2006, Combretum imberbe, South African Biodiversity Institute, Walter Sisulu National Botanical Garden, South African National Biodiversity Institute, Roodepoort.

Notten, A. \& Xaba, P.M., 2003, Lessertia frutescens, South African Biodiversity Institute, Kirstenbosch National Botanical Garden, South African Nationa Biodiversity Institute, Cape Town.

Opoku, J.K., Addai-Mensah, P. \& Wiafe, F., 2013, 'Traditional and Modern Medicine: A survey of views on its integration in Ghana', Medicine 4(2), 256-257.

Ozioma, E.O.J. \& Chinwe, O.A.N., 2019, 'Herbal Medicines in African traditional medicine', Herbal Medicine 10, 191-214. https://doi.org/10.5772/intechopen. 80348

Pal, R., Mohanta, P.K., Sarker, G., Rustagi, N. \& Ghosh, A., 2015, 'Traditional healers and evidence-based medicine', American Journal of Public Health Research 3(5A), 194-198. https://doi.org/10.12691/ajphr-3-5A-41

Perveen, S., Al-Taweel, A.M., Fawzy, G.A., El-Shafae, A.M., Khan, A. \& Proksch, P., 2015, 'Cytotoxic glucosphingolipid from Celtis Africana', Pharmacognosy Magazine 11(1), S1-S5. https://doi.org/10.4103/0973-1296.157662

Pretorius, E., 1991, 'Traditional and modern medicine working in tandem', Curationis 14(4), 10-13. http://doi.org/10.4102/curationis.v14i4.339

Priya, M.L., Priya, K.B., Kotakadi, V.S. \& Josthna, P., 2015, 'Herbal and medicinal plants molecules towards treatment of cancer: A mini review', American Journal of Ethnomedicine 2(2), 136-142.

Raimondo, D., Von Staden, L., Foden, W., Victor, J.E., Helme, N.A., Turner, R.C. et al., 2009, Red list of South African plants, Strelitzia 25, South African Nationa Biodiversity Institute, Pretoria.

Ouellet, C., Saïas, T., Sit, V., Lamothe, L., Rapinski, M., Cuerrier, A. et al., 2018, 'Access to indigenous and allopathic medicines: A systematic review of barriers and facilitators', Global Journal of Community Psychology Practice 9(2), 1-38.

Pheage, T., 2017, Dying from lack of medicines: Encouraging local production, right policies the way out, viewed 17 March 2021, from https://www.un.org/ africarenewal/magazine/december-2016-march-2017/dying-lackmedicines.
Puataweepong, P., Sutheechet, N. \& Ratanamongkol, P., 2012, 'A survey of complementary and alternative medicine use in cancer patients treated with radiotherapy in Thailand', Evidence-Based Complementary and Alternative Medicine 2012, 670408. https://doi.org/10.1155/2012/670408

Sant, D.W., Mustafi, S., Gustafson, C.B., Chen, J., Slingerland, J.M. \& Wang, G., 2018 Vitamin C promotes apoptosis in breast cancer cells by increasing TRAlL expression', Science Reports 8, 5306. https://doi.org/10.1038/s41598-018-23714-7

Science in Africa, 2008, Could SA plants hold the secret to a new cancer drug?, Science magazine for Africa.

Semenya, S.S., Maroyi, A., Potgieter, M.J. \& Erasmus, L.J.C., 2013, 'Herbal medicines used by Bapedi traditional healers to treat reproductive ailments in the Limpopo province, South Africa, African Journal of Traditional Complementary and Alternative Medicines 10(2), 331-339. https://doi.org/10.4314/ajtcam.v10i2.19

Sewram, V., 2019, The cancer conundrum, African Cancer Institute at the Faculty of Medicine and Health Sciences, Stellenbosch University, Stellenbosch.

Smith, P., 2003, 'The use of herbal OTC products in South Africa: Main topic', CME: Your SA Journal of CPD 21(2), 89-95.

Steenkamp, V. \& Gouws, M.C., 2006, 'Cytotoxicity of six South African medicinal plant extracts used in the treatment of cancer', South African Journal of Botany 72(4), 630-633. https://doi.org/10.1016/j.sajb.2006.02.004

Stefan, D.C., 2015, 'Why is cancer not a priority in South Africa?', South African Medical Journal 105(2), 103-104. https://doi.org/10.7196/SAMJ.9301

Steyn, M. \& Muller, A., 2000, 'Traditional healers and cancer prevention', Curationis 23(3), 4-11. https://doi.org/10.4102/curationis.v23i3.675

Street, R.A. \& Prinsloo, G., 2012, ‘Commercially important medicinal plants of South Africa: A review', Journal of Chemistry 2013, 205048. https://doi. org/10.1155/2013/205048

Sylla, B.S. \& Wild, C.P., 2012, 'Cancer burden in Africa in 2030: Invest today and save tomorrow', African Journal of Cancer 4, 1-2. https://doi.org/10.1007/s12558012-0199-4

Tavakoli, J., Miar, S., Majid Zadehzare, M. \& Akbari, H., 2012, 'Evaluation of effectiveness of herbal medication in cancer care: A review study', Iran Journal of Cancer Prevention 5(3), 144-156.

Telles, S., Pathak, S., Singh, N. \& Balkrishna, A., 2014, 'Research on traditional medicine: What has been done, the difficulties, and possible solutions', EvidenceBased Complementary and Alternative Medicine 2014, 1-5. https://doi. org/10.1155/2014/495635

Thring, T.S.A. \& Weitz, F.M., 2006, 'Medicinal plant use in the Bredasdorp/Elim region of the Southern Overberg in the Western Cape Province of South Africa', Journal of Ethnopharmacology 103(2), 261-275. https://doi.org/10.1016/j.jep.2005.08.013

Trimble, E.L. \& Rajaraman, P., 2017, 'Integrating traditional and allopathic medicine: An opportunity to improve global health in cancer', Journal of the National Cance Institute Monographs 2017(52), 9-10. https://doi.org/10.1093/jncimonographs/ $\lg 011$

Turner, S., 2001, Leonotis leonurus, South African National Biodiversity Institute, Roodepoort.

Valadez-Vega, C., Delgado-Olivares, L., González, J.A.M., García, E.M., Ibarra, J.R.V., Moreno, E.R. et al., 2013, 'The role of natural antioxidants in cancer disease', in J.A. Morales-Gonzalez (ed.), Oxidative stress and chronic degenerative diseases-A role for antioxidants, pp. 391-419, IntechOpen, Rijeka.

Van Wyk, B.E., 2011, 'The potential of South African plants in the development of new medicinal products', South African Journal of Botany 77(4), 812-829. https://doi. org/10.1016/j.sajb.2011.08.011

West, H., 2018, 'Complementary and alternative medicine in cancer care', JAMA Oncology 4(1), 139. https://doi.org/10.1001/jamaoncol.2017.3120

Williams, V.L., Raimondo, D., Crouch, N.R., Cunningham, A.B., Scott-Shaw, C.R., Lotter, M. et al., 2008, Curtisia dentata (Burm.f.) C.A. Sm, National Assessment, Red List of South African plants version 2017, p. 1, South African National Biodiversity Institute.

Williams, V.L., Raimondo, D., Crouch, N.R., Cunningham, A.B., Scott-Shaw, C.R. Lotter, M. \& Ngwenya, A.M., 2016, Hypoxis hemerocallidea, Fisch., C.A. Mey. \& Ave-Lall. National assessment: Red List of South African plants version 2017, South African National Biodiversity Institute.

World Health Organisation (WHO), 2013, Traditional medicine, report by the Secretariat.

Xaba, V.M., 2016, 'Pharmacological screening of traditional medicinal plants used against skin ailments in the Free State, South Africa', Master degree minidissertation, Department of Plant Sciences, University of the Free. 